\title{
Wolbachia diversity in the Porcellionides pruinosus complex of species (Crustacea: Oniscidea): evidence for host-dependent patterns of infection
}

\author{
ALICE MICHEL-SALZAT, RICHARD CORDAUX \& DIDIER BOUCHON* \\ Laboratoire de Génétique et Biologie des Populations de Crustacés, UMR CNRS 6556, Université de Poitiers, \\ 40 avenue du Recteur Pineau, F-86022 Poitiers cedex, France
}

\begin{abstract}
Porcellionides pruinosus is a cosmopolitan woodlouse. It is known to exhibit patterns of geographical variation between populations, and has been suspected to consist of several very closely related species. This species was found to carry Wolbachia endosymbionts, alpha-proteobacteria which are known to modify the reproduction of their crustacean hosts by inducing cytoplasmic incompatibility or feminization. In the P. pruinosus complex, Wolbachia induced feminization, but two different patterns of infection were reported: high prevalence and presence of infected males, or low prevalence and absence of infected males. In this study we investigated nine populations described as Porcellionides pruinosus carrying different Wolbachia strains, with the aim of investigating the possibility of coevolution between symbionts and hosts. Molecular analyses were carried out on both Wolbachia DNA (wsp gene) and host mitochondrial DNA (mt LSU rDNA). We show that (1) the nine host populations exhibited a high genetic differentiation so that they have to be split into two sibling species; (2) three different Wolbachia strains were found in the host complex but were not species-specific; and (3) the pattern of infection by Wolbachia was more host-dependent than symbiont-dependent.
\end{abstract}

Keywords: coevolution, genetic hitchhiking, molecular phylogenies, Porcellionides pruinosus, terrestrial isopod, Wolbachia, sibling species.

\section{Introduction}

The cosmopolitan terrestrial isopod Porcellionides (= Metoponorthus) pruinosus has a confused taxonomic history (Vandel, 1962). This species is highly synanthropic and is considered to be the most widely distributed species of terrestrial isopods (Vandel, 1962; Garthwaite \& Sassaman, 1985). Originally native to Asia Minor (Vandel, 1962) and carried extensively elsewhere by humans, $P$. pruinosus has colonized the entire world except the polar regions. It presents important geographical variation and is considered to be a polytypic species. Based on morphological criteria about 20 subspecies were recognized throughout the world (Vandel, 1962) although the validity of these subspecies remains questionable (Böhme, 1978). More recently several observations supported the presence of distinct species (Garthwaite \& Sassaman, 1985; Juchault et al., 1985; Marcadé et al., 1999).

*Correspondence E-mail: didier.bouchon@univ-poitiers.fr
As far as is known, all the studied populations of this species complex harbour Wolbachia bacteria. Wolbachia are intracytoplasmic alpha-proteobacteria which are maternally inherited and can alter the reproduction of their hosts. In the case of $P$. pruinosus, they are believed to induce the feminization of genetic males (Rigaud et al., 1997; Marcadé et al., 1999). Two different patterns of infection seem to be present in $P$. pruinosus populations, named type 1 and type 2 in the following text. Type 1 was found in all the French host populations examined: Wolbachia were present both in males and females, with a $90 \%$ prevalence (Rigaud et al., 1997; Marcadé et al., 1999). Type 2 was found in Greece, Tunisia and Réunion Island host populations: Wolbachia were detected in females only, and the prevalence was only 60\% (Marcadé et al., 1999). These two groups of host populations and their associated patterns of infection could be well separated by mitochondrial RFLP analysis. On the other hand, two Wolbachia strains belonging to the B super group of Wolbachiae were found in P. pruinosus (Marcadé et al., 
1999; Cordaux et al., 2001). These results have led the authors to hypothesize a possible correlation between Wolbachia lineages inducing different phenotypes, and differentiated populations in the $P$. pruinosus group (Marcadé et al., 1999). However, the high genetic divergence recorded between the two Wolbachia strains involved suggested possible horizontal transmission rather than common origin.

The aims of the present study were (1) to check the genetic differentiation of both hosts and parasites on a larger scale; (2) to determine the infection patterns in the host populations; and (3) to test the hypothesis of coevolution of P. pruinosus and Wolbachia as previously suggested by Marcadé et al. (1999). This was accomplished by analysing the sequences of mitochondrial LSU rDNA host genes, shown to be an adequate marker for this taxonomic level (Michel-Salzat \& Bouchon, 2000) and to be more reliable than RFLP analysis. At the same time, a molecular analysis of the Wolbachia strains found in the host populations was carried out by sequencing the wsp gene, a rapidly evolving gene encoding a Wolbachia surface protein (Braig et al., 1998). On the basis of these two analyses, the correlation between the infection pattern and the Wolbachia strains is then examined and discussed.

\section{Materials and methods}

\section{Sampling and Wolbachia detection}

Nine populations from Tunisia (Tunis), Spain (Manzanares), Réunion Island (Saint Paul), Israel (Haifa), Greece (Athens) and France (Nevers, Montamisé, Celles-sur-Belle, Camarade) were studied (see Table 1). Camarade, Manzanares and Haifa were new collecting sites, whereas additional sampling was studied in populations previously investigated (i.e. Nevers and Celles-sur-Belle, Rigaud et al., 1997; Athens, Tunis and
Saint-Paul, Marcadé et al., 1999). Total DNA was obtained by standard phenol extraction and ethanol precipitation (Kocher et al., 1989) from muscles, nerve tissue and gonads of each individual. PCR assays were performed to test for the presence of Wolbachia, using two specific primer sets for the 16S rDNA and wsp genes (O'Neill et al., 1992; Zhou et al., 1998). Positive and negative controls using known infected and uninfected isopods (Armadillidium vulgare, laboratory strains) were performed with each set of PCR reactions.

\section{Sequencing}

Individuals testing positive for Wolbachia were used for both host mitochondrial and Wolbachia gene sequencing. The 3'-half end of the LSU rDNA region of the host's mitochondrial DNA was amplified using the specific primers 16Sar and 16Sbr (Xiong \& Kocher, 1991). PCR was conducted as previously described (Michel-Salzat \& Bouchon, 2000). The wsp region of the Wolbachia DNA was amplified using the specific primers wsp81F and wsp691R (Braig et al., 1998).

After purification, the double-stranded PCR products were sequenced on both strands with the amplification primer set, using the ABI Prism BigDye terminator cycle sequencing kit (PE Applied Biosystems, Foster City). Sequences were analysed on a ABI 310 automated sequencer. For each specimen, sequences were obtained independently at least twice from different PCR products.

Mitochondrial sequences were deposited in EMBL, GenBank and DDBJ databases under accession numbers AJ275207 to AJ275212 (Table 1). Two sequences used in analyses were previously obtained from the Cellessur-Belle and Saint Paul populations (AJ388107 and AJ388108, Michel-Salzat \& Bouchon, 2000). Wsp sequences were deposited in EMBL, GenBank and DDBJ databases under accession numbers AJ300579 to AJ300585 (Table 1). Two sequences were previously

Table 1 Origin and number of Porcellionides pruinosus sampled, presence of Wolbachia (the number testing positive is in parentheses) and accession numbers in EMBL, GenBank and DDBJ databases for host and Wolbachia genes

\begin{tabular}{|c|c|c|c|c|c|}
\hline \multirow[b]{2}{*}{ Locality } & \multirow{2}{*}{$\begin{array}{l}\text { Geographical } \\
\text { position }\end{array}$} & \multicolumn{2}{|c|}{ Presence of Wolbachia } & \multicolumn{2}{|c|}{ Accession number } \\
\hline & & Males & Females & Mt LSU rDNA & $w s p$ gene \\
\hline Nevers (F) & $46^{\circ} 59^{\prime} \mathrm{N}, 3^{\circ} 10^{\prime} \mathrm{E}$ & $3(2)$ & $14(10)$ & AJ300578 & AJ300581 \\
\hline Montamisé (F) & $46^{\circ} 37^{\prime} \mathrm{N}, 0^{\circ} 25^{\prime} \mathrm{E}$ & - & $6(4)$ & AJ275208 & AJ276604 \\
\hline Celles-sur-Belle (F) & $46^{\circ} 15^{\prime} \mathrm{N}, 0^{\circ} 14^{\prime} \mathrm{W}$ & $2(2)$ & $9(9)$ & AJ388107 & AJ300585 \\
\hline Camarade (F) & $43^{\circ} 04^{\prime} \mathrm{N}, 1^{\circ} 16^{\prime} \mathrm{E}$ & $6(1)$ & $4(1)$ & AJ275207 & AJ300580 \\
\hline Manzanares (E) & $40^{\circ} 00^{\prime} \mathrm{N}, 4^{\circ} 00^{\prime} \mathrm{W}$ & $6(4)$ & 7 (7) & AJ275209 & AJ300579 \\
\hline Athens (GR) & $37^{\circ} 56^{\prime} \mathrm{N}, 23^{\circ} 36^{\prime} \mathrm{E}$ & $10(0)$ & $10(6)$ & AJ275211 & AJ300583 \\
\hline Tunis (TN) & $36^{\circ} 50^{\prime} \mathrm{N}, 10^{\circ} 15^{\prime} \mathrm{E}$ & $5(0)$ & $5(3)$ & AJ275210 & AJ300582 \\
\hline Haifa (ISR) & $32^{\circ} 50^{\prime} \mathrm{N}, 35^{\circ} 00^{\prime} \mathrm{E}$ & - & $1(1)$ & AJ275212 & AJ300584 \\
\hline St Paul, Réunion (F) & $21^{\circ} 00^{\prime} \mathrm{N}, 55^{\circ} 17^{\prime} \mathrm{E}$ & $11(0)$ & $11(8)$ & AJ388108 & AJ276605 \\
\hline
\end{tabular}

(C) The Genetics Society of Great Britain, Heredity, 87, 428-434. 
obtained from the Montamisé and Saint Paul populations (AJ276604 and AJ276605, Cordaux et al., 2001).

\section{Alignment and phylogenetic inferences}

LSU rDNA sequences from $P$. pruinosus were manually aligned with the sequence of Porcellionides cingendus (no. AJ388106), previously shown to be an appropriate outgroup (Michel-Salzat \& Bouchon, 2000). Wsp sequences were manually aligned, taking into account the coding structure of the gene. The sequence of Dysdera erythrina symbionts (no. AJ276615) belonging to the A super group of Wolbachiae was added as outgroup (Cordaux et al., 2001). The corresponding data matrices (10 host sequences of 430 sites including gaps, 120 variable sites; 10 parasite sequences of 588 sites including gaps, 135 variable sites) were separately tested using the MODELTEST 3.0 software (Posada \& Crandall, 1998) for a model of DNA substitution.

Phylogenetic trees were inferred using PAUP* 4.02B software (Swofford, 1998). Tree reconstructions were performed using maximum parsimony, maximum likelihood and distance methods using the General Time Reversible GTR model (Rodriguez et al., 1990). Bootstrap analyses were performed with 1000 replicates (Felsenstein, 1985). A Mantel test (Mantel, 1967) was performed with GENETIX 4.01 software (Belkhir, 2000) in order to estimate the correlation between the two distance matrices from parasite and host phylogenies (10 000 permutations).

\section{Results}

\section{Infection status}

All the populations were carrying Wolbachia. Infected males were only found in French and Spanish populations (i.e. Nevers, Celles-sur-Belle, Camarade and Manzanares) whereas no male was detected positive for Wolbachia in southern populations (i.e. Athens, Tunis and Saint-Paul; Table 1). The difference between these two infection patterns in males was significant $\left(\chi^{2}=17.4\right.$, d.f. $\left.=1, P<0.001\right)$. The presence of infected males in French and Spanish populations indicated that they corresponded to the type 1 infection. There is no difference in infection rates in males in these four populations $\left(\chi^{2}=5.62\right.$, d.f. $\left.=3, P>0.05\right)$. Southern populations with uninfected males corresponded to the type 2 infection. Assuming a 95\% confidence limit, the maximum likelihood frequency of a positive male being present in these samples is therefore 10.8\% (Post \& Millest, 1991). Comparing the type of infection (type 1 vs. type 2) there was no difference in infection rate in females $\left(\chi^{2}=1.48\right.$, d.f. $\left.=1, P>0.05\right)$. In the same way, when males and females were pooled, there was no significant difference in prevalence among populations $\left(\chi^{2}=11.99\right.$, d.f. $\left.=6, P>0.05\right)$.

\section{Host diversity}

The alignment of LSU rDNA sequences from P. pruinosus revealed a first group of identical sequences that included French (Nevers, Montamisé, Celles-sur-Belle, Camarade) and Spanish (Manzanares) populations (Table 2). The second group of sequences corresponded to populations from Réunion Island (Saint Paul), Greece (Athens), and Tunisia (Tunis), with only one substitution between the Tunisian sequence and the others. The sequence obtained from the Israeli population (Haifa) exhibited a divergence of $22.5 \%$ with those of the second group and a divergence of $16.5 \%$ with those of the first group. The first and second groups differed by a mean divergence of $20.8 \%$ (Table 2).

All the procedures used for phylogenetic reconstruction resulted in the same inferred tree (Fig. 1b). Two groups of populations were clearly separated, the first one comprising the Montamisé, Celles-sur-Belle, Manzanares, Camarade, Nevers and Haifa populations

Table 2 Matrix of total nucleotide differences of mitochondrial sequences (below diagonal) and Wolbachia sequences (above diagonal) for populations of Porcellionides pruinosus

\begin{tabular}{lccrrrrrrr}
\hline & $\mathrm{N}(\mathrm{F})$ & $\mathrm{Mo}(\mathrm{F})$ & $\mathrm{Ce}(\mathrm{F})$ & $\mathrm{Ca}(\mathrm{F})$ & $\mathrm{Ma}(\mathrm{E})$ & $\mathrm{A}(\mathrm{GR})$ & $\mathrm{T}(\mathrm{TN})$ & $\mathrm{H}(\mathrm{ISR})$ & $\mathrm{S}(\mathrm{F})$ \\
\hline Nevers (F) & - & 121 & 121 & 27 & 27 & 2 & 0 & 2 & 2 \\
Montamisé (F) & 0 & - & 0 & 121 & 121 & 121 & 121 & 121 & 121 \\
Celles-sur-Belle (F) & 0 & 0 & - & 121 & 121 & 121 & 121 & 121 & 121 \\
Camarade (F) & 0 & 0 & 0 & - & 0 & 29 & 27 & 29 & 29 \\
Manzanares (E) & 0 & 0 & 0 & 0 & - & 29 & 27 & 29 & 29 \\
Athens (GR) & 88 & 88 & 88 & 88 & 88 & - & 2 & 0 & 0 \\
Tunis (TN) & 89 & 89 & 89 & 89 & 89 & 1 & - & 2 & 2 \\
Haifa (ISR) & 71 & 71 & 71 & 71 & 71 & 96 & 97 & - & 0 \\
St Paul, Réunion (F) & 88 & 88 & 88 & 88 & 88 & 0 & 1 & 96 & - \\
\hline
\end{tabular}

N, Nevers; Mo, Montamisé; Ce, Celles-sur-Belle; Ca, Camarade; Ma, Manzanares; A, Athens; T, Tunis; H, Haifa; S, St Paul. 
(group PpA, for P. pruinosus haplotype A), the second one comprising the Tunis, Athens and Saint Paul populations (group $P p \mathrm{~B}$, for $P$. pruinosus haplotype B). Nodes were supported by high bootstrap values $(>95 \%)$. The nucleotide divergence observed between the two mitochondrial lineages $(20.8 \%)$ was similar to the distance separating all populations of $P$. pruinosus from the outgroup $P$. cingendus (from 22 to $24 \%$ ). Assuming a molecular clock of about $2 \%$ of divergence per Myr (Simon et al., 1994; Ballard \& Kreitman, 1995), the two haplotypes could have diverged $10 \mathrm{Myr}$ ago. However, the variation in the molecular clock across taxa suggests taking this result with caution. A calibration of the molecular clock in Oniscidea, with biogeographical and palaeontological data, would be necessary to obtain a fully reliable estimation.

\section{Wolbachia diversity}

The alignment of the wsp DNA sequences revealed four different sequences corresponding to three groups (Table 2). The first group corresponded to Wolbachia isolated from Athens, Tunis, Haifa, St-Paul and Nevers P. pruinosus populations. Wolbachia from Tunis and Nevers exhibited the same wsp sequence and showed a divergence of $0.3 \%$ with the other strains of this group. Wolbachia from Camarade and Manzanares exhibited the same $w s p$ sequence and showed a divergence of $4.8 \%$ with the first group (Table 2). The third group included Wolbachia from the Celles-sur-Belle and Montamisé populations which exhibited the same wsp sequence. This last group was highly divergent from the others (pairwise distance $=20.6 \%$ ).
All the procedures used for phylogenetic reconstruction gave the same inferred tree (Fig. 1a). Three strains were clearly identified and supported by high bootstrap values. The first strain included the symbionts found in southern populations (Athens, Tunis and Saint-Paul) as well as the symbionts from Haifa and Nevers. This strain was called $w$ PruI (for Wolbachia P. pruinosus I) according to the nomenclature of Zhou et al. (1998). The second strain, called $w$ PruII, grouped the bacteria found in the Camarade and Manzanares populations. The last strain comprising the Montamisé and Cellessur-Belle symbionts was called $w$ PruIII.

\section{Comparison between host mitochondrial lineages and bacterial strains}

Comparison of $P$. pruinosus and Wolbachia relationships (Fig. 1) revealed that the $P p \mathrm{~B}$ group of populations (St-Paul, Athens, and Tunis) was infected only by the $w$ PruI strain of Wolbachia. The PpA group of populations was found to carry the three different strains of Wolbachia. The Mantel test confirmed that genetic distances of hosts and symbionts were not correlated $\left(r^{2}=0.125, \quad P=0.761\right)$, thus that the observed patterns of distribution can not be explained by co-speciation.

\section{Discussion}

We clearly identified three Wolbachia strains in the $P$. pruinosus complex. The comparison of the relationships of hosts and bacteria showed that the Wolbachia strains could not be strictly attributed to one or the other host lineages. The $w$ PruI strain observed in the
Fig. 1 Phylogenetic relationships among Wolbachia strains and Porcellionides pruinosus haplotypes, showing distribution of infection patterns. Infection patterns: ${ }^{1}$, type 1 , Wolbachia in males; ${ }^{2}$, type 2, no Wolbachia in males; *, type of infection unknown.

Fig. 1(a) Maximum likelihood tree $(-\log$ likelihood $=1674.84)$ obtained from the $w s p$ sequences. $w$ PruI, $w$ PruII, $w$ PruIII are Wolbachia strains of P. pruinosus (see text). Bootstrap values (1000 replicates) are shown above nodes. (b) Maximum likelihood tree $(-\log$ likelihood $=1382.77)$ obtained from partial sequences of $\mathrm{mt}$ LSU rDNA. $P p$ A and $P p$ B are mitochondrial lineages of $P$. pruinosus (see text). Bootstrap values (1000 replicates) are shown above nodes. (a)

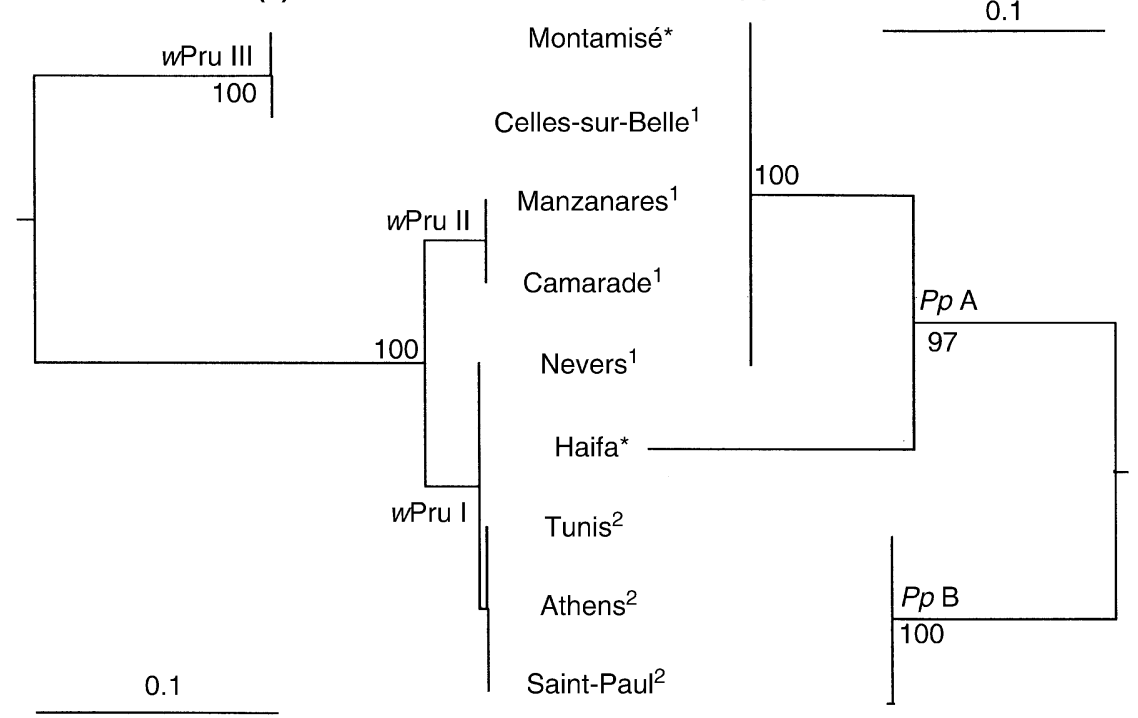

(C) The Genetics Society of Great Britain, Heredity, 87, 428-434. 
$P p$ B group of host populations was also found in two samples of the $P p$ A group (Haifa, Nevers) and host populations of the $P p A$ group harboured the three different strains of Wolbachia. Furthermore, the distribution of Wolbachia strains can not be explained only by coevolution and probably involved several infestation events. The most parsimonious hypothesis requires two infestation events: an ancestral infection by the $w$ PruI strain might have occurred, followed by a cospeciation leading to the $w$ PruII strain. More recently, a second infection might have occurred by host switching of the distantly related $w$ PruIII strain. This scenario is strengthened by previous analyses of Wolbachia phylogenetic relationships, which revealed that the $w$ PruIII strain is closely related to insect Wolbachia strains and could result from recent interspecific transfers (Bouchon et al., 1998; Cordaux et al., 2001). On the other hand, the $w$ PruI and $w$ PruII strains were closely related, belonging to a woodlice-specialized Wolbachia clade (Cordaux et al., 2001; Bouchon et al., 1998).

Two different infection patterns were recorded which can not be related to variation in prevalence, but instead only in presence or absence in males. Infection patterns were not correlated with Wolbachia distribution (Fig. 1), since the same pattern was associated with the two very distantly related strains $w$ PruII and $w$ PruIII, whereas the two most related strains $w$ PruI and $w$ PruII were associated with two different infection patterns. This suggests that the pattern of infection is mainly mediated by the host and not by the Wolbachia strain. The best evidence appears in the $w$ PruI clade even if we can not totally preclude a slight Wolbachia effect because of the low differentiation of $w s p$ sequences between Nevers strain (pattern 1) and the southern ones (pattern 2). As the $w$ PruII strain belongs to the feminizer clade of Wolbachia (Bouchon et al., 1998; Cordaux et al., 2001), host mediated pattern is also probable in the Manzanares and Camarade populations. The presence of the $w$ PruIII strain in both sexes in the Celles-sur-Belle population could either be because of a host effect or because this Wolbachia strain has never been a feminizer. A host mediated pattern of infection has already been suggested in woodlice (Rigaud et al., 1999) and in insects (Fialho \& Stevens, 2000). Because the feminizing process involves competition between a bacterial product and the male hormone (Juchault \& Legrand, 1985), the two infection patterns could be due to differences in hormonal target. A high variability of the androgenic hormone was recently reported in the Oniscidea (Martin \& Juchault, 1999). The host mediated patterns of infection shown in this paper could therefore be the result of a differentiation of the androgenic hormone in the two $P$. pruinosus sibling species. Moreover, host resistance against feminizing Wolbachia has been hypo- thesized in some cases and might have occurred in the P. pruinosus complex (Rigaud et al., 1997).

The molecular analysis of a mitochondrial gene clearly revealed the existence of two distinct groups of $P$. pruinosus populations ( $P p \mathrm{~A}$ vs. $P p \mathrm{~B}$ ) separated by the high genetic distance of $20.8 \%$. When comparing the same portion of the mitochondrial LSU rDNA in crustaceans, a divergence of $0.5 \%$ is observed between two branchiopod species (Palmero et al., 1988; Perez et al., 1994), whereas a divergence of $11 \%$ is observed between two decapod species (Machado et al., 1993). Within the Oniscidea, the pairwise distances were $3 \%$ between two populations of the same species (Armadillidium vulgare) and $7.4 \%$ between two subspecies (Porcellio dilatatus dilatatus and P. d. petiti) (MichelSalzat \& Bouchon, 2000). The higher divergence value found here in $P$. pruinosus corresponds to those observed between species within a given genus (e.g. from 22 to $24 \%$ between $P$. cingendus and $P$. pruinosus populations, this study; $22 \%$ between two Armadillidium species, Michel-Salzat \& Bouchon, 2000). This result supports the existence of two distinct species in the studied populations of $P$. pruinosus, which is congruent with Marcadé et al. (1999). As no clear morphological features have been found to separate the two species, they correspond to the definition of sibling species (Dobzhansky et al., 1968). Our molecular data suggest that the divergence between the two species may have occurred during the Miocene (10 Myr ago). As the genus Porcellionides originates from Asia Minor (Vandel, 1962) the interfertility of populations from Tunis and Réunion Island (Marcadé et al., 1999) suggests a recent introduction of specimens from the Mediterranean zone to Réunion Island. This may have occurred by means of natural expansion due to the facility of woodlice for rafting on floating vegetation (Taiti et al., 1992), or more probably by way of human migration (Schmalfuss \& Ferrara, 1978). According to our data, the sibling species seems to be present in Israel and Western Europe. However, mainly due to the synanthropy of these animals, phylogeographic considerations on their actual distribution are difficult to clarify.

There is some empirical evidence for the role of Wolbachia in speciation in the Drosophila simulans complex (Hoffmann \& Turelli, 1988), between Nasonia species (Breeuwer \& Werren, 1990) and in the terrestrial isopod Porcellio dilatatus (Legrand \& Juchault, 1986). Host speciation by Wolbachia-induced incompatibility has been recently demonstrated (Bordenstein et al., 2001) between two closely related species of Nasonia. As all the studied samples were carrying Wolbachia, the reproductive isolation in $P$. pruinosus populations (Marcadé et al., 1999) could therefore be related to 
Wolbachia effects on their hosts. However, by hitchhiking the mitochondria because they are associated cytoplasmic genomes, feminizing Wolbachia could promote the fixation of mitochondrial mutations (Werren, 1997). The only phenotype described in P. pruinosus up to date is feminization (Rigaud et al., 1997; Marcadé et al., 1999). Considering the distribution of Wolbachia strains in the two host species as well as the incongruent phylogenetic relationships of Wolbachia and their hosts (maybe due to recent Wolbachia horizontal transfer), we conclude that it is very unlikely that feminizing Wolbachia were involved in the differentiation of the two sibling species. Alternatively, we can suggest an ancestral CI-inducing Wolbachia acting in P. pruinosus speciation which could secondarily evolve to a feminizing phenotype. However this latter scenario seems highly hypothetical.

\section{Acknowledgements}

We thank T. Rigaud and J. B. Whitfield for helpful comments on the manuscript.

\section{References}

BALLARD, J. W. O. AND KREITMAN, M. 1995. Is mitochondrial DNA a strictly neutral marker? Trends Ecol. Evol., 10, 485-488.

BELKHIR, K. 2000. GENETIX, logiciel sous Windows $^{\mathrm{TM}}$ pour la génétique des populations. Laboratoire Génome et Populations, CNRS UPR 9060, Université de Montpellier II, Montpellier, France.

BÖHME, w. 1978. Kühnelt's principle of regional stenoecy and its bearing on the subspecies problem: a theoretical approach. Z. Zool. Syst. Evolforsch., 16, 256-266.

BORDENSTEIN, S. R., O'HARA, P. F. AND WERREN, J. H. 2001. Wolbachia-induced incompatibility precedes other hybrid incompatibilities in Nasonia. Nature, 409, 707-710.

BOUCHON, D., RIGAUD, T. AND JUCHAULT, P. 1998. Evidence for widespread Wolbachia infection in isopod crustaceans: molecular identification and host feminization. Proc. $R$. Soc., 265, 1081-1090.

BRAIG, H. R., ZHOU, w., DOBSON, S. L. AND O'NEILL, S. L. 1998. Cloning and characterisation of a gene encoding the major surface protein of the bacterial endosymbiont Wolbachia pipientis. J. Bacteriol., 180, 2373-2378.

BREEUWER, J. A. J. AND WERREN, J. H. 1990. Microorganism associated with chromosome destruction and reproductive isolation between two insect species. Nature, 346, 558-560.

CORDAUX, R., MICHEl-SAlZAT, A. AND BOUCHON, D. 2001. Wolbachia infection in crustaceans: novel hosts and potential routes for horizontal transmission. J. Evol. Biol., 14, 237-243.

DOBZHANSKY, T., EHRMAN, L. AND KASTRITSIS, P. 1968. Ethological isolation between sympatric and allopatric species of the obscura group of Drosophila. Anim. Behav., 16, 79-87.
FELSENSTEIN, J. 1985. Confidence limits on phylogenies: an approach using the bootstrap. Evolution, 39, 783-791.

FIALHO, R. F. AND STEVENS, L. 2000. Male-killing Wolbachia in a flour beetle. Proc. R. Soc. B, 267, 1469-1473.

Garthwaite, R. AND Sassaman, C. 1985. Porcellionides floria, new species, from north America; provinciality in the cosmopolitan isopod Porcellionides pruinosus (Brandt). J. Crustacean Biol., 5, 539-555.

HOFFMANN, A. A. AND TURELLI, M. 1988. Unidirectional incompatibility in Drosophila simulans: inheritance, geographic variation and fitness effects. Genetics, 119, 435-444.

JUCHAUlT, P. AND LEGRAND, J. J. 1985. Contribution à l'étude du mécanisme de l'état réfractaire à l'hormone androgène chez Armadillidium vulgare Latr. (Crustacé Isopode Onisco) hébergeant une bactérie féminisante. Gén. Comp. Endocrinol., 60, 463-467.

JUCHAULT, P. AND MOCQUARD, J. P. AND KOUIGAN, S. 1985. Etude expérimentale de l'influence des facteurs externes (température et photopériode) sur le cycle de reproduction du crustacé onisco Porcellionides pruinosus (Brandt) provenant de populations africaine (Togo) et européenne (France). Crustaceana, 48, 307-315.

KOCHER, T. D., THOMAS, W. K., MEYER, A., EDWARDS, S. V. ET $A L$. 1989. Dynamics of mitochondrial DNA evolution in animals: amplification and sequencing with conserved primers. Proc. Natl. Acad. Sci. U.S.A., 86, 6196-6200.

LEGRAND, J. J. AND JUCHAUlt, P. 1986. Rôle de bactéries symbiotiques dans l'intersexualité, la monogénie et la spéciation chez des crustacés onisco. Bull. Zool., 53, 161-172.

MACHADO, E. G., DENNEBOUY, N., SUAREZ, M. O., MOUNOULOU, J. C. ET $A L$. 1993. Mitochondrial 16S-rRNA gene of two species of shrimps: sequences variability and secondary structure. Crustaceana, 65, 279-286.

MANTEL, N. 1967. The detection of disease clustering and generalised regression approach. Cancer Res., 27, 209-220.

MARCADÉ, I., SOUTY-GROSSET, C., BOUCHON, D., RIGAUD, T. ET AL. 1999. Mitochondrial DNA variability and Wolbachia infection in two sibling woodlice species. Heredity, 83, 71-78.

MARTIN, G. AND JUCHAUlt, P. 1999. Androgenic hormone specificity in terrestrial isopods (Oniscidea): systematic involvements. J. Crust. Biol., 19, 684-689.

MICHEL-SALZAT, A. AND BOUCHON, D. 2000. Phylogenetic analysis of mitochondrial LSU rRNA in oniscids (Crustacea Isopoda). C. R. Acad. Sci., 323, 827-837.

O'NEILl, S. L., GIORDANO, R., COLBERT, A. M. E., KARR, T. L. ET $A L$. 1992. 16S rRNA phylogenetic analysis of the bacterial endosymbionts associated with cytoplasmic incompatibility in insects. Proc. Natl. Acad. Sci. USA, 89, 2699-2702.

PALMERO, I., RENART, J. AND SASTRE, L. 1988. Isolation of cDNA clones for mitochondrial $16 \mathrm{~S}$ ribosomal RNA from the crustacean Artemia. Gene, 68, 239-248.

PEREZ, M. L., VAlverde, J. R., BATUeCAS, B., AMAT, F. ET $A L$. 1994. Speciation in the Artemia genus: mitochondrial DNA analysis of bisexual and parthenogenetic brine shrimps. J. Mol. Evol., 38, 156-168.

POSADA, D. AND CRANDALL, K. A. 1998. MODELTEST: testing the model of DNA substitution. Bioinformatics, 14, 817-818. 
POST, R. J. AND MILleSt, A. L. 1991. Sample size in parasitological and vector surveys. Parasitol. Today, 7, 141.

RigAUd, T., ANTOINE, D., MARCADÉ, I. AND JUCHAUlt, P. 1997. The effect of temperature on sex ratio in the isopod Porcellionides pruinosus: environmental sex determination or by-product of cytoplasmic sex determination. Evol. Ecol., 11, 205-215.

RIGAUD, T., BOUCHON, D., SOUTY-GROSSET, C. AND RAIMOND, R. 1999. Mitochondrial DNA polymorphism, sex ratio distorters and population genetics in the isopod Armadillidium vulgare. Genetics, 152, 1669-1677.

RODRIGUEZ, F., OLIVER, J. F., MARIN, A. AND MEDINA, J. R. 1990. The general stochastic model of nucleotide substitutions. J. Theor. Biol., 142, 485-501.

SCHMALFUSS, H. AND FERRARA, F. 1978. Terrestrial Isopods from west Africa. II. Families Tylidae, Ligidae, Trichoniscidae, Styloniscidae, Rhyscotidae, Halophilosciidae, Philosciidae, Platyarthridae, Trachelipidae, Porcellionidae, Armadillidiidae. Italian J. Zool., 2, 15-97.

SIMON, C., FRATI, F., BECKENBACH, A., CRESPI, B. ET AL. 1994. Evolution, weighting, and phylogenetic utility of mito- chondrial gene sequences and a compilation of conserved polymerase chain reaction primers. Ann. Entomol. Soc. Am., 87, 651-701.

SWOFFORD, D. L. 1998. PAUP*: Phylogenetic Analysis Using Parsimony (*and Other Methods). Sinauer Associates, Sunderland, MA.

TAITI, S., FERRARA, F. AND KWON, D. H. 1992. Terrestrial Isopoda (Crustacea) from the Togian Islands, Sulawesi, Indonesia. Invertebrate Taxonomy, 6, 787-842.

vANDEL, A. 1962. Isopodes terrestres, Deuxième partie, vol. 66. E. P. Lechevalier, Paris.

WERREN, J. H. 1997. Wolbachia and speciation. In: Howard, D. and Berlocher, S. (eds) Endless Forms: Species and Speciation, pp. 245-260. Oxford University Press, New York.

XIONG, B. AND KOCHER, T. D. 1991. Comparison of mitochondrial DNA sequences of seven morphospecies of black flies (Diptera: Simulidae). Genome, 34, 306-311.

ZHOU, W., ROUSSET, F. AND O'NEILL, S. L. 1998. Phylogeny and PCR based classification of Wolbachia strains using wsp gene sequences. Proc. R. Soc. B, 265, 509-515. 